\title{
DYNAMIC RESPONSE OF A MULTIPLE CRACKED CANTILEVER
}

\section{BEAM}

\author{
Ch. Ratnam ${ }^{1}$, G. Nageswara Rao $^{2}$, BSN Murthy ${ }^{3}$, V. Vital Rao ${ }^{4}$ \\ ${ }^{1}$ Professor, Dept. of Mechanical Engineering, Andhra University, Visakhapatnam, India. \\ ${ }^{2}$ Assistant Professor, Dept. of Mechanical Engineering, Vignan's Lara Inst.Of Tech. \& Science, Guntur, India. \\ ${ }^{3}$ Associate Professor, Dept. of Mechanical Engineering, GITAM University, Visakhapatnam, India \\ ${ }^{4}$ Sr. Manager, Vizag Steel Plant, Visakhapatnam, India
}

\begin{abstract}
Dynamic response information is useful in structural health monitoring to identify the location and magnitude of damage. Estimation of natural frequency of structure is very important for vibration based damage detection and is not usually calculated simply and can sometimes be complicated. In the present approach a cantilever beam is illustrated with aFinite element model (FEM) andalso a general MATLAB program is developed for multiple cracked cantilever beamto obtain eigenvalues and eigenvectors. The results obtained by using FEM through MATLAB computer program are validated with experimental results.Experimentation is conducted on cantilever beam for both damaged and undamaged cases by using Laser Doppler vibrometer (LDV).The recorded signal isanalyzed by signal processing in VibSoft to measure the frequency response. It is observed that the natural frequencies of the system decreases with increase in crack size. The theoretical values are very much close to experimental values. The results are presented in the form of tables and graphs for each case.
\end{abstract}

Keywords:Dynamic response, Crack, Cantilever beam, FEM, LDV.

\section{INTRODUCTION}

For non-destructive testing of mechanical systems, it is necessary to know the dynamic response of the system such as natural frequencies and mode shapes. The natural frequencies and mode shapes can be directly used to predict the nature of the damage existing within the system. Because ofthe high sensitivity of these two parameters, damage alters the frequencies of the structures even with small change in stiffness and mass of the system.

The dynamic response is used directly inconventional damage detection methods which are measured from experiment and/or numerical techniques. An overview of the various damage detection methods using system's modal parameters was given by Doebling et al. to estimate the crack size and location [1]. Most of the authors utilized frequency changes which are obtained from both analytical and experimental modal tests. Srinivas, et al. [2-9] employed modal data to identify damage location and extent in residual force concept. The damage estimation methods are predominately based on the change in natural frequencies. Sinha, et al. [10] address the crack theory and research work on crack detection based on the change in natural frequencies.Sutar [11] analyzed the cracked cantilever beam using finite element analysis by giving the relationship between the modal natural frequency and the crack depth at different locations. Most of the authors considered change in stiffness of the damaged structure only to identify the damage location and severity. Ge and Lui[12] used dynamic response information such as frequencies and mode shapes of the structure in its damaged state caused by change in the structure's mass and stiffness properties.Chirstides and Barr
[13] have modeled the beam structure with cracks at different locations by using Euler- Bernoulli beam elements with some modifications to the local flexibility in the vicinity of the crack.

Gilbert et.al [14]reported the results in damage detection for simple structures using only one accelerometer experimentally and also using FEM and analytical method.Chasalevris and Papadopoulos [15] have studied the dynamic behavior of a cracked beam with two transverse surface cracks. Each crack is characterized by its depth, position and relative angle. A local compliance matrix of two degrees of freedom, bending in the horizontal and the vertical planes is used to model the rotating transverse crack in the shaft and is calculated based on the available expressions of the stress intensity factors and the associated expressions for the strain energy release rates.

Ruotolo et al.[16] has investigated forced response of a cantilever beam with a crack that fully opens or closes, to determine depth and location of the crack by considering left end of the beam is cantilevered and right end is free. The harmonic sine force was applied on the free end of the beam. Vibration amplitude of the free end of the beam was taken into consideration. Rizoset al. [17] has determined the crack location and its depth in a cantilever beam from the vibration modes by measuring the flexural vibrations of rectangular cross-section with a transverse surface crack. Analytical results are used to relate the measured vibration modes to the crack location and depth. From the measured amplitudes at two points of the structure vibrating at one of its natural modes, the respective vibration frequency and an analytical solution of the dynamic response, the crack 
location can be found and depth can be estimated with satisfactory accuracy.Ostachowach et al. [18] have studied the comprehensive surveys of crack modeling approaches. The simplest method for FE model is to use a reduced stiffness matrix for a complete element to simulate a small crack in the element.In this paper a MATLAB program is developed to computing eigenvaluesand eigenvectors for a cantilever beam with multiple cracksafter validate with experimentation.

\section{Mathematical Background}

The governing equation of motion of a beam having $n$ degrees of freedom for forced vibration can be writtenas

$[\mathrm{M}]\{\ddot{\mathrm{x}}(\mathrm{t})\}+[\mathrm{C}]\{\dot{\mathrm{x}}(\mathrm{t})\}+[\mathrm{K}]\{\mathrm{x}(\mathrm{t})\}=\mathrm{F}(\mathrm{t})$

Where $[\mathrm{M}],[\mathrm{C}]$ and $[\mathrm{K}]$ are mass, damping and stiffness matrices of the system, $\{\mathrm{x}(\mathrm{t})\}$ is displacement vector, and $\mathrm{F}(\mathrm{t})$ is applied load vector.Neglecting damping and forcein Eq.(1)for a free undamped vibration problem. The requiredcharacteristic equation can be derived from Eq. (1) as follows

$\left[\mathrm{K}-\lambda_{\mathrm{i}} \mathrm{M}\right] \varphi_{\mathrm{i}}=0$

Where $[\mathrm{K}]$ and $[\mathrm{M}]$ are the global stiffness and mass matrix, $\lambda_{\mathrm{i}}$ and $\varphi_{\mathrm{i}}$ are the $\mathrm{i}^{\text {th }}$ mode eigenvalue and eigenvector respectively.

\subsection{Finite Element Formulation}

The cantilever beam is modeled for Finite Element Method. The elemental stiffness and mass matrix for uncracked and cracked beam are formulated in the following section. The undamaged elemental stiffness and mass matrix are given as

$$
\begin{gathered}
k_{e}=\frac{E I}{l^{3}}\left[\begin{array}{cccc}
12 & 6 l_{\mathrm{e}} & -12 & 6 l_{\mathrm{e}} \\
6 l_{\mathrm{e}} & 4 l_{\mathrm{e}}^{2} & -6 l_{\mathrm{e}} & 2 l_{\mathrm{e}}^{2} \\
-12 & -6 l_{\mathrm{e}} & 12 & -6 l_{\mathrm{e}} \\
6 l_{\mathrm{e}} & 2 l_{\mathrm{e}}^{2} & -6 l_{\mathrm{e}} & 4 l_{\mathrm{e}}^{2}
\end{array}\right] \\
m_{e}=\frac{\rho A l}{420}\left[\begin{array}{cccc}
156 & 22 l_{\mathrm{e}} & 54 & -13 l_{\mathrm{e}} \\
22 l_{\mathrm{e}} & 4 l_{\mathrm{e}}^{2} & 13 l_{\mathrm{e}} & -3 l_{\mathrm{e}}^{2} \\
54 & 13 l_{\mathrm{e}} & 156 & -22 l_{\mathrm{e}} \\
-13 l_{\mathrm{e}} & -3 l_{\mathrm{e}}^{2} & -22 l_{\mathrm{e}} & 4 l_{\mathrm{e}}^{2}
\end{array}\right]
\end{gathered}
$$

Where $\mathrm{E}=$ Modulus of elasticity, $\mathrm{I}=$ moment of inertia of the section, $l_{e}=$ length of element, $\rho=$ mass density of the beam material, $A=$ cross-sectional area of the beam element. Theelemental stiffness is reduced whenever damage occurred in beam, the damagedelemental stiffness matrix is written as

$\left[\mathrm{k}_{\mathrm{d}}\right]=\left[\mathrm{k}_{\mathrm{e}}\right]-\left[\mathrm{k}_{\mathrm{c}}\right]$

Where $\left[\mathrm{k}_{\mathrm{d}}\right],\left[\mathrm{k}_{\mathrm{e}}\right]$ are the stiffness matrices for the damaged and undamaged element, $\left[\mathrm{k}_{\mathrm{c}}\right]$ is the reduction in the stiffness matrix due to the crack in terms of the crack position and depth [10].The stiffness matrix is obtained using the standard integration based on the variation in flexural rigidity .Thereforethe stiffness matrix $\left[\mathrm{k}_{\mathrm{c}}\right]$ is given as

$$
\mathrm{k}_{\mathrm{c}}=\left[\begin{array}{cccc}
\mathrm{K}_{11} & \mathrm{~K}_{12} & -\mathrm{K}_{11} & \mathrm{~K}_{14} \\
\mathrm{~K}_{21} & \mathrm{~K}_{22} & -\mathrm{K}_{12} & \mathrm{~K}_{24} \\
-\mathrm{K}_{11} & -\mathrm{K}_{12} & \mathrm{~K}_{11} & -\mathrm{K}_{14} \\
\mathrm{~K}_{14} & \mathrm{~K}_{24} & -\mathrm{K}_{14} & \mathrm{~K}_{44}
\end{array}\right]
$$

The proposed method does not affect the mass distribution of the beam i.e the elemental mass matrix is unaltered.

\section{Experimental Procedure}

The frequency response of the cantilever beam is measured experimentally to validate the finite element modeling. An illustrative case of a cantilever beam frequency response ismeasured by using Laser Doppler vibrometer (LDV). Experimentation is conducted on cantilever beamwithout damage and thenrepeatedthe procedure for single and multiple cracks. The beam was excited with impact hammer and recorded the vibration signal in LDV. Later, the recorded signal was analyzed by signal processing in VibSoft to measure the frequency response. Data wererecorded for both undamaged and partially damaged beamto assess the effect of damage on dynamic characteristics of systems. The experimental setup for measuring natural frequency using LDV as shown in Fig.1.

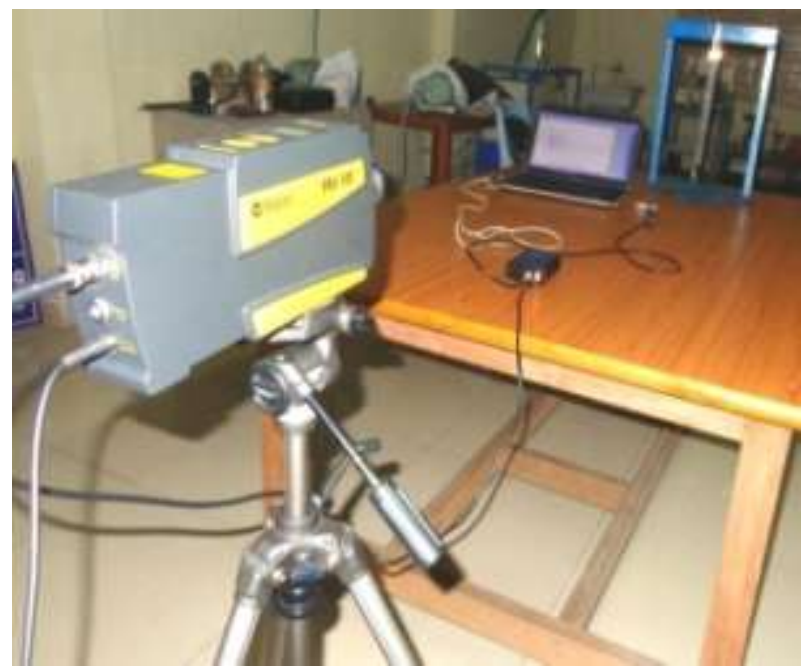

a) Laser Doppler Vibrometer



b) Cantilever beam

Fig.1. Experimental setup 


\section{RESULTS AND DISCUSSIONS}

\subsection{Finite Element Analysis}

The methodology is illustrated with considering a cantilever beam, which is discretised into 10elements. This leads to a finite element model containing 20 degrees of freedom (10 translations and 10 rotations)and the beam is depicted in Fig.2. Properties of the beam chosen are as follows. Modulus of elasticity $\mathrm{E}=207 \mathrm{GPa}$, cross sectional area $\mathrm{A}=$ $1.5 \times 10^{-4} \mathrm{~m}^{2}$, moment of inertia $\mathrm{I}=4.5 \times 10^{-10} \mathrm{~m}^{4}$, density $\rho$ $=7800 \mathrm{~kg} / \mathrm{m}^{3}$ and total length of the beam $l=0.385 \mathrm{~m}$. Three different situations for this case are considered as i) the beam is in a state of undamage,ii)the beam having element 2 damaged partially to an extent of $30 \%$ iii), the beam is having elements 2 and 3 damaged partially to an extent of $20 \%$ and $30 \%$ respectively. Now finite element analysis is performed to solve the eigenproblem of these conditions and the modal data are shown in Table1and Fig.3. It is observed from numerical technique that the natural frequency decreases with increase in damage size and no of cracks.



Fig.2. Cantilever Beam

\subsection{Experimental Measurements}

The natural frequencies of the damaged and undamaged cantilever beam were measured experimentally by using laser Doppler vibrometer (LDV). The frequency of each case was obtained from the FFT spectrum analyzer. It is observed from experiment that the natural frequency decreases with increase in damage size. The results present in table 1 and a comparison of measured frequency response as shown in Fig. 4, 5 and 6.The experimental and theoretical values are presented in table1 and graphs (Fig. 3)

Table.1.The natural frequencies $(\mathrm{Hz})$ of the damaged and undamagedcantilever beam.

\begin{tabular}{|c|c|c|c|c|c|c|}
\hline \multirow{2}{*}{$\begin{array}{c}\text { S. } \\
\text { no }\end{array}$} & \multicolumn{2}{|c|}{ Undamaged } & \multicolumn{4}{|c|}{ Damaged } \\
\cline { 2 - 7 } & \multicolumn{2}{|c|}{} & \multicolumn{2}{|c|}{ Single crack } & \multicolumn{2}{c|}{ Multiple cracks } \\
\cline { 2 - 7 } & Theo & Exp & Theo & Exp & Theo & Exp \\
\hline 1 & 34.20 & 35.08 & 32.98 & 33.87 & 32.19 & 33.22 \\
\hline 2 & 211.00 & 213.11 & 207.57 & 209.99 & 195.52 & 197.66 \\
\hline 3 & 593.06 & 594.86 & 565.72 & 570.33 & 560.88 & 567.49 \\
\hline 4 & 1172.60 & 178.21 & 1138.41 & 1145.45 & 1098.63 & 1101.33 \\
\hline 5 & 1945.87 & 1951.74 & 1874.29 & 1881.61 & 1834.41 & 1837.42 \\
\hline
\end{tabular}



Fig.3. Comparison of frequency response of a).no crack,b).single crack,c) .multiple cracks

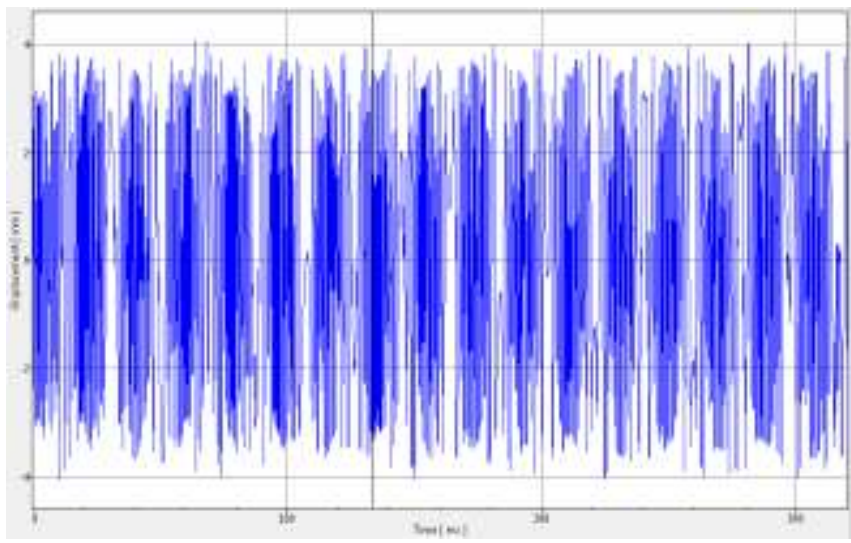

Fig.4. measured displacement in time domain

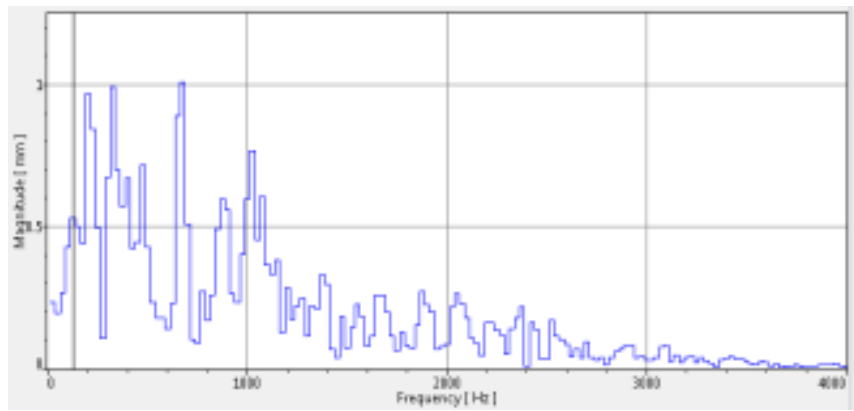

Fig. 5. Frequency response of undamaged cantilever beam

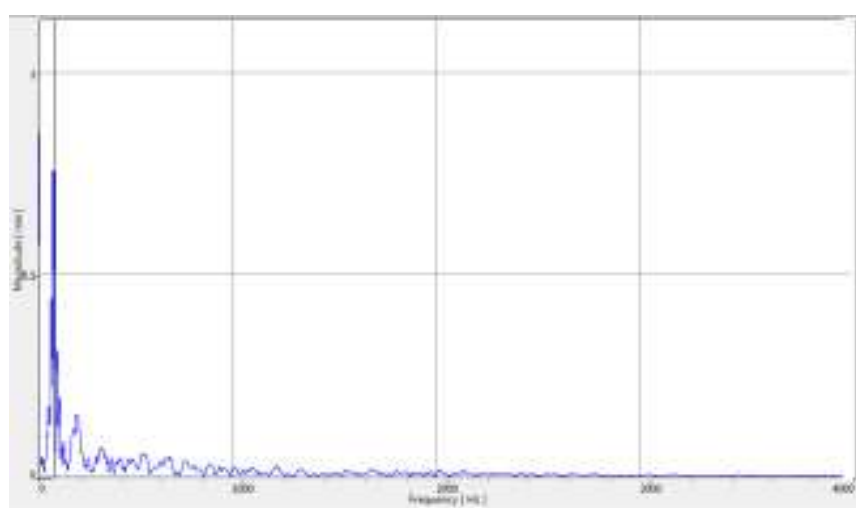

Fig. 6. Frequency response of damaged cantilever beam

\section{CONCLUSIONS}

In this paper, a finite element formulation was adopted and then a computer code was developed for calculating and simulating cracks inthe cantilever beam. If the crackis considered on the cantilever beam, the frequencies of the beam are reduced. With the same crack depth, the frequency reduction value of multiple cracks is lower than that of single crack. Experimentation was conducted on cantilever beam using Laser Doppler Vibrometer. It was observed that a considerable variation in eigenvalues and eigenvectors even for a small changes in stiffness from both experimental and finite element analysis. The frequency of the cracked cantilever beam decreases with increase in the crack size for all modes of vibration. Experimental values are coinciding very close with theoretical values. 


\section{REFERENCES}

[1] S.W.Doebling, C.R.Farrar and M.B.Prime, 'Areview of vibration summary based damage detection', Shock and vibration digest 30,91-105, 1998.

[2] J.Srinivas, Ch.Ratnam and B.S.N. Murthy, 'Damage identification using Fourier coefficients of response', Jjournal of sound and vibration 303, 909-917,2007.

[3] BS Ben, BA Ben, C. Ratnam and SH Ynag, 'Ultrasonic based method for damage identification in composite materials', J. of mechanics and materials in Design, 8 (4), 297-309, 2012.

[4] C. Ratnam and P. Rao, 'Identification of damage in structures using genetic algorithms', Journal of the institution of Engineers (India), 84, 154-160, 2004.

[5] PS Rao and C. Ratnam, 'Health monitoring of welded structures using statisticral process control', Mechanical systems and Signal processing, 27, 683-695, 2012.

[6] C.Ratnam,J.Srinivas and BSN Murthy, 'Damage detection in mechanical system using Fourier coefficients' Journal of sound and vibration 303,909917,2007.

[7] BS Ben,SH Yang,C Ratnamand BA Ben 'Ultrasonic based structural damage detection using combined finite element and model $\mathrm{d}$ Lamb wave propagation parameters in composite The international journal of Advanced Manufacturing Technology 67 (5-8), 2011.

[8] PS Rao and C Ratnam 'Vibration Based Damage Identification using Berg's algorithm and Shewshart control charts', Journal of ASTM International, 8 (4), 112, 2011.

[9] C Ratnam, BS Ben and BA Ben, 'Optimization of lamb wave propagation parameters for damage detection in composite materials', JP Journal of solids and structures, 2 (1), 69-82, 2008.

[10]J.K.Sinha, M.I Friswell and S.Edwards, 'Simplified models for the logatiocation of cracks in beam structures using measured vibration data', Journal of sound and vibration,251(1), 13-38, 2002.

[11]Mihir Kumar Sutar, Finite Element Analysis of a cracked cantilever beam International Journal of Advanced Engineering Research and /studies vol.1/Issue II/January-march, 2012/285-289.

[12]MaGe;EricM.Luistructuraldamage identification using system dynamic properties.Comouter\& Structures 83(2005)2185-2196.

[13]S.Christides and A. D. S. Barr 1984 International Journal of Mechanical Science 26, 639-648. One dimensional theory of cracked Bernoulli-Euler beams.

[14]Gilbert- Rainer Gillich, ZemoPraisach and Darian M. Onchis about the effectiveness of Damage Detection Methods Based on vibration measurements.

[15]ChasalevrisAthanasios C. and Papadopoulos Hris A., Identification of multiple cracks in beams under bending, Mechanical systems and Signal Processing 20, (2006), pp. 1631-1673.

[16]Ruotoloret.al. Harmonic analysis of the vibrations of a cantilevered beam with a closing crack, Compact Struct, 61(6), (1996), pp.1057-1074.

[17]Rizos P.F., Aspragathos N., and Dimaroganas A.D., Identification of racked Location and magnitude in a
Cantilever beam from the vibrational modes, Journal of Sound and Vibration, 138 (3), (1989), pp.381-388.

[18]W.Ostachowichand M. Krawczuk, 'Modeling of structural stiffness loss due to damage', $4^{\text {th }}$ International Conference on Damage Assessment of Structures, Cardiff, 185-199. 2011. 